\title{
Phase-field study of the pattern formation in Al-Ag-Cu under the influence of the melt concentration
}

\author{
Philipp Steinmetz ${ }^{\mathrm{a}}$, Michael Kellner ${ }^{\mathrm{a}}$, Johannes Hötzer ${ }^{\mathrm{a}, \mathrm{b}, *}$, Anne Dennstedt $^{\mathrm{c}}$, \\ Britta Nestler ${ }^{\mathrm{a}, \mathrm{b}}$ \\ ${ }^{a}$ Institute for Applied Materials (IAM), Karlsruhe Institute of Technology (KIT), \\ Haid-und-Neu-Str. 7, 76131 Karlsruhe, Germany \\ ${ }^{b}$ Institute of Materials and Processes, Karlsruhe University of Applied Sciences, \\ Moltkestrasse 30, D 76133 Karlsruhe, Germany \\ ${ }^{c}$ Deutsches Zentrum für Luft- und Raumfahrt e.V. (DLR), Institut für Materialphysik im \\ Weltraum, Linder Höhe, 51170 Köln, Germany
}

\begin{abstract}
In single transverse sections of directional solidified ternary eutectics, various microstructure patterns can be observed. These patterns influence the mechanical properties and it is therefore of interest to gain a better understanding of the microstructure formation process. It is assumed that local variations in the concentration of the melt lead to different patterns. To investigate this effect, large-scale three-dimensional phase-field simulations of directional solidification in the vicinity of the ternary eutectic point of $\mathrm{Al}-\mathrm{Ag}-\mathrm{Cu}$ are applied. The different arising patterns from the simulations are compared and analyzed with statistical methods. The simulations show different stable patterns within a range of $\pm 1 \%$ of the melt concentration around the ternary eutectic point. The same tendencies are observed in experimental micrographs.
\end{abstract}

Keywords: directional solidification, phase-field, ternary eutectic alloy, $\mathrm{Al}-\mathrm{Ag}-\mathrm{Cu}$, pattern selection, melt concentration

${ }^{*}$ Corresponding author. Tel.: +49 721 608-45315; Fax: +49 721 608-44364; email: johannes.hoetzer@kit.edu

Preprint submitted to Computational Materials Science

July 15, 2016 


\section{Introduction}

Different microstructures evolve, during the solidification of multicomponent systems. These microstructures influence the mechanical properties of the macroscopic component [1]3. Especially in the vicinity of a ternary eutectic

5 point a wide range of patterns in the microstructure form during directional solidification.

Five theoretical arrangements of the three solid phases in ternary eutectic systems are predicted from geometrical assumptions in [4] and are graphically depicted in [5]. In the experimental study of [6], the pattern formation in various ternary eutectic systems is presented. Several of the theoretically predicted arrangements are found in the evolving patterns of the ternary eutectic system $\mathrm{Al}-\mathrm{Ag}-\mathrm{Cu}$. The influence of the growth rate on the evolving patterns is investigated in [7 9] and the crystallographic orientation of the patterns is studied with EBSD in [10. Statistical analyses to classify the phase arrangements are conducted with nearest neighbor statistics [11, with shape factors [12], polar plots [13] as well as with Fourier analyses [14]. Six different, experimentally observed patterns in the system $\mathrm{Al}-\mathrm{Ag}-\mathrm{Cu}$ are characterized and investigated in [15. First three-dimensional representations of the microstructure in $\mathrm{Al}-\mathrm{Ag}-\mathrm{Cu}$, obtained from synchrotron tomography, are reported in [16]. A thermodynamic assessment is applied in [17, 18].

Simulative research of the pattern formation in three-phase ternary eutectics with the phase-field method is conducted in 3D for idealized systems in [1923 and for $\mathrm{Al}-\mathrm{Ag}-\mathrm{Cu}$ in 23 26]. In idealized systems of directionally solidified ternary eutectics, various patterns are found in 20] and the influence of the concentration of the melt and the solid-liquid interface energies on the pattern formation is identified in [23]. With large-scale simulations, visual 25] and quantitative [26] accordance between phase-field simulations and experiments can be achieved. The necessity of large-scale simulations to obtain statistical volume elements (SVE) is presented in [26] with principal component analysis based on two-point correlations. In [22] different alignments of a hexagonal pat- 
tern in single transverse sections of an ideal system are reported for large-scale simulations.

Beside the different alignments, also various patterns are found within a single micrograph parallel to the solidification front as depicted in fig. 1 for the system $35 \mathrm{Al}-\mathrm{Ag}-\mathrm{Cu}$. In the upper right corner, paw structures and in the lower left part, chain-like structures evolve in a concurrent manner. It is assumed, that these structures are separated by a grain boundary. The sample solidified under uniformly imprinted process conditions with a growth velocity of $0.32 \mu \mathrm{m} / \mathrm{s}$ and a gradient of $2.8 \mathrm{~K} / \mathrm{mm}$.

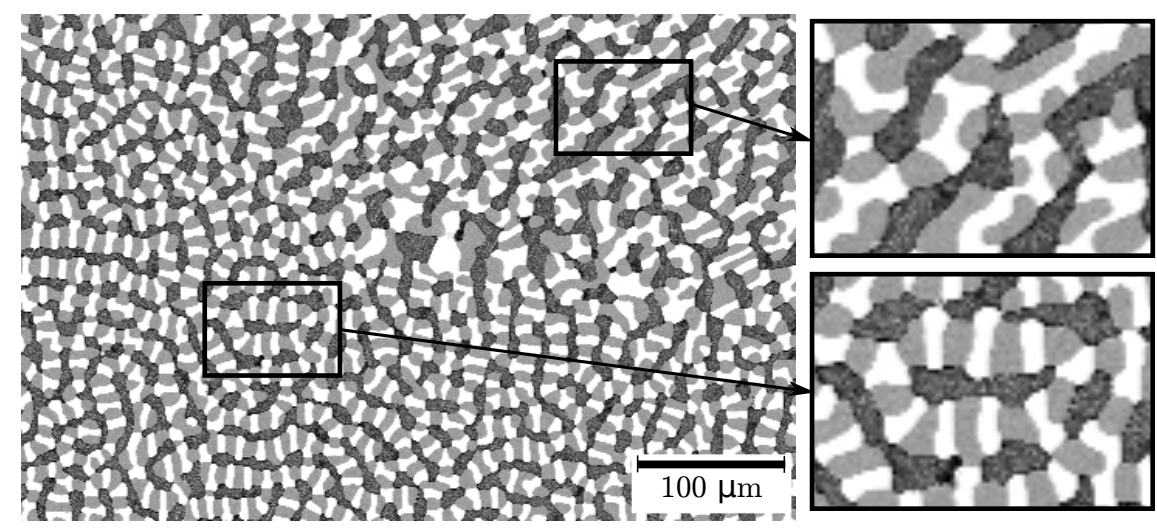

Figure 1: Experimental transverse section of a directionally solidified microstructure in the ternary eutectic system Al-Ag-Cu, with a velocity of $0.32 \mu \mathrm{m} / \mathrm{s}$ and a gradient of $2.8 \mathrm{~K} / \mathrm{mm}$. Three solid phases $\mathrm{Ag}_{2} \mathrm{Al}$ (white), $\mathrm{Al}_{2} \mathrm{Cu}$ (gray) and $\mathrm{Al}$ (black) can be distinguished. In the upper right corner, paw structures and in the lower left part, chain-like structures are observed and exemplary extracted as magnified images. It is assumed, that these structures are separated by a grain boundary.

40 To investigate the simultaneous formation of different patterns under uniformly imprinted process conditions, the effect of various melt concentrations is studied. Therefore, we apply large-scale three-dimensional phase-field simulations based on the Grand potential approach and systematically vary the concentration of the melt in the vicinity of the ternary eutectic point. To quantify the evolving patterns, the phase fractions, nearest neighbor statistics and principal component analysis, based on two-point correlations are applied. 


\section{Model}

For the simulations, a thermodynamically consistent phase-field model is used, derived from a Grand potential functional and Allen-Cahn type variation [25, 27, 28]. For a three-phase ternary eutectic system, the $N=4$ orderparameters $\phi_{\alpha}$, describe the local phase fractions. From the mass balance of the concentrations and Fick's law, the $K=3$ chemical potentials in $\boldsymbol{\mu}$ are derived. Coupling the $N$ phase-fields, the $K$ chemical potentials and the imprinted temperature $T$, results in the following set of evolution equations:

$\tau \epsilon \frac{\partial \phi_{\alpha}}{\partial t}=\underbrace{-\epsilon T\left(\frac{\partial a(\phi, \nabla \phi)}{\partial \phi_{\alpha}}-\nabla \cdot \frac{\partial a(\boldsymbol{\phi}, \nabla \boldsymbol{\phi})}{\partial \nabla \phi_{\alpha}}\right)-\frac{1}{\epsilon} T \frac{\partial \omega(\phi)}{\partial \phi_{\alpha}}-\sum_{\beta=1}^{N} \psi_{\beta}(\boldsymbol{\mu}, T) \frac{\partial h_{\beta}(\boldsymbol{\phi})}{\partial \phi_{\alpha}}}_{:=r h s_{\alpha}}-\frac{1}{N} \sum_{\beta=1}^{N} r h s_{\beta}$,

$$
\begin{aligned}
\frac{\partial \boldsymbol{\mu}}{\partial t}= & {\left[\sum_{\alpha=1}^{N} h_{\alpha}(\phi)\left(\frac{\partial \boldsymbol{c}_{\alpha}(\boldsymbol{\mu}, T)}{\partial \boldsymbol{\mu}}\right)\right]^{-1}\left(\nabla \cdot\left(\boldsymbol{M}(\boldsymbol{\phi}, \boldsymbol{\mu}, T) \nabla \boldsymbol{\mu}-\boldsymbol{J}_{a t}(\boldsymbol{\phi}, \boldsymbol{\mu}, T)\right)\right.} \\
& \left.-\sum_{\alpha=1}^{N} \boldsymbol{c}_{\alpha}(\boldsymbol{\mu}, T) \frac{\partial h_{\alpha}(\phi)}{\partial t}-\sum_{\alpha=1}^{N} h_{\alpha}(\phi)\left(\frac{\partial \boldsymbol{c}_{\alpha}(\boldsymbol{\mu}, T)}{\partial T}\right) \frac{\partial T}{\partial t}\right) \\
\frac{\partial T}{\partial t}= & \frac{\partial}{\partial t}\left(T_{0}+G(z-v t)\right)=-G v
\end{aligned}
$$

The relaxation parameter $\tau$ is introduced, to couple the different timescales of the evolution equations. The shape of the diffuse interface between the phases is modeled by the gradient energy $a$, by the obstacle potential $\omega$ and $\varepsilon$, which controls the interface width. The driving force for the phase transitions is described by the differences of the Grand potentials $\psi_{\beta}$, which are calculated from the Gibbs energies of the different phases. The Gibbs energies are incorporated from thermodynamic CALPHAD databases [17, 18, and, to optimize the computational effort, fitted by a parabolic approach of the form:

$$
G_{\alpha}(\boldsymbol{c}, T)=\left\langle\boldsymbol{c}, \boldsymbol{\Xi}_{\alpha}(T) \boldsymbol{c}\right\rangle+\left\langle\boldsymbol{c}, \boldsymbol{\xi}_{\alpha}(T)\right\rangle+X_{\alpha}(T),
$$

with the matrix $\boldsymbol{\Xi}_{\alpha}(T)$, the vector $\boldsymbol{\xi}_{\alpha}(T)$, the scalar $X_{\alpha}(T)$ and the scalar product $\langle\cdot, \cdot\rangle[29$ The evolution equation of the chemical potentials is derived in 
(2), including the mobility term $\boldsymbol{M}$, the anti-trapping current $\boldsymbol{J}_{a t}$ [28, 30, 31] and the interpolation function $h_{\alpha}$. Starting from an initially imprinted temperature field with the base temperature $T_{0}$, the temperature $T$ evolves with the gradient $G$ and the velocity $v$ in the growth direction $z$. The partial differential equations (PDEs) (1)-(3), are spatially discretized with finite differences and the temporal evolution is calculated with a forward Euler scheme [32]. These PDEs are implemented in the massive parallel framework WALBERLA 33. A detailed description of the model is presented in [25].

\section{Setup}

In the following, the simulation setup and the applied parameters for the concentration variations are introduced.

\subsection{Simulation setting}

The setup for the simulations of the ternary eutectic directional solidification

70 is schematically depicted in fig. 2. The simulation domain has a base size of $800 \times 800$ voxel cells. To obtain statistical volume elements these large-scale simulations are required to minimize the influence of the periodic boundary conditions, as shown in 22, 26]. Starting from an initial Voronoi tesselation, to model the nucleation, three solid phases cooperatively grow in $z$-direction with a defined velocity, controlled by the temperature gradient.

\subsection{Parameters}

The system $\mathrm{Al}-\mathrm{Ag}-\mathrm{Cu}$ exhibits a ternary eutectic point $E_{\text {cal }}$ at the molfractions $0.181,0.691$ and $0.128(\mathrm{Ag}, \mathrm{Al}, \mathrm{Cu})$ as depicted in the liquidus projection in fig. 3. based on the CALPHAD database of [17, 18]. At a temperature $20 \mathrm{~K}$ below the eutectic point $E_{c a l}$, the solubility of $\mathrm{Ag}$ in the $A l$-phase has changed from $16.9 \%$ to $8 \%$, leading to different phase fractions at room temperature. This solubility shift is described in [11, 17, 18. To reproduce the phase fractions reported from micrographs, the ternary eutectic point is shifted to $E_{E x p}$ with the mol-fractions $0.237,0.622,0.141(\mathrm{Ag}, \mathrm{Al}, \mathrm{Cu})$ analogues to [23, 25]. This 


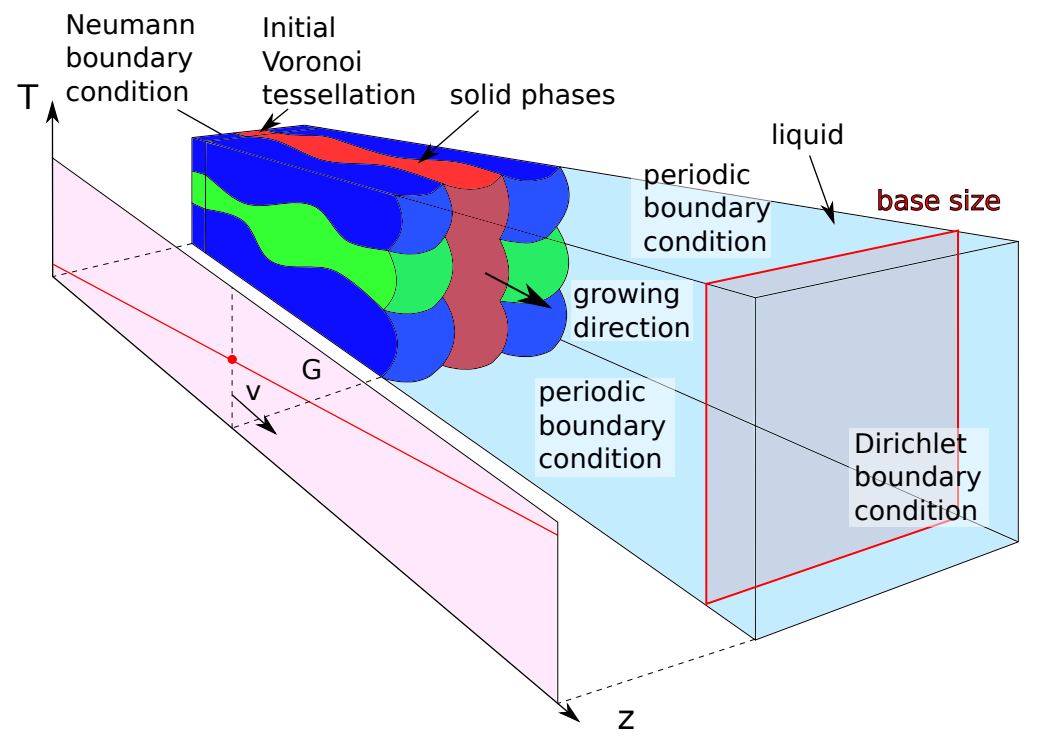

Figure 2: Schematically depiction of the setting applied in the simulations.

85 allows to reduce the computational effort significantly.

According to [17, 18], the parameters for the shifted and adjusted parabolic Gibbs energies $\boldsymbol{\Xi}_{\alpha}, \boldsymbol{\xi}_{\alpha}, X_{\alpha}$ as well as the interface energies $\boldsymbol{\gamma}$, the model-intrinsic higher order term $\gamma_{\alpha \beta \delta}$ to suppress the unphysical evolving of third-phases [19, 34. 35, the diffusion coefficient $\boldsymbol{D}$ and the process parameters $\nabla T$ and $v$ are listed in table 1. The numerical parameters are given in table 2

In the simulations, the concentration of the melt $\boldsymbol{c}_{\ell}$ is systematically varied in the vicinity of the ternary eutectic composition at $E_{E x p}$, following the three axis parallel to the edges of the ternary simplex. One concentration is kept constant and the other two are changed by $\pm 0.5 \%$ and $\pm 1 \%$ respectively. The changes of $\pm 0.5 \%$ are indicated by small labels a-f and of $\pm 1 \%$ by capital letters $A-F$, as highlighted by the enlargement in fig. 3 .

\section{Results}

All simulations are conducted with $800 \times 800$ voxels base size and 3 million time steps, corresponding to a growth height of approximately 6300 cells. They 
Table 1: Summary of the physical parameters used in the simulations. The concentrations of the melt are varied by $\pm 0.5 \%$ and $\pm 1 \%$ respectively, according to fig. 3

\begin{tabular}{|c|c|c|c|c|c|c|}
\hline \multirow[t]{2}{*}{ Parameter } & \multicolumn{5}{|c|}{ Simulation value } & \multirow[t]{2}{*}{ Physical value } \\
\hline & phase & $A l$ & $A g_{2} A l$ & $\mathrm{Al}_{2} \mathrm{Cu}$ & liquid & \\
\hline \multirow{4}{*}{$\gamma$} & $A l$ & - & 0.5 & 0.4 & 0.2 & \multirow{4}{*}{$\begin{array}{l}\text { scaling factor for physical } \\
\text { values: } 0.2 \mathrm{~J} / \mathrm{m}^{2} \text { based on } 36+39\end{array}$} \\
\hline & $\mathrm{Ag}_{2} \mathrm{Al}$ & 0.5 & - & 0.4 & 0.4 & \\
\hline & $\mathrm{Al}_{2} \mathrm{Cu}$ & 0.4 & 0.4 & - & 0.4 & \\
\hline & liquid & 0.3 & 0.4 & 0.4 & - & \\
\hline$\gamma_{\alpha \beta \delta}$ & \multicolumn{5}{|l|}{6.5} & $2.6 \mathrm{~J} / \mathrm{m}^{2}$ \\
\hline$D$ & \multicolumn{5}{|l|}{5.0} & $7.5 \cdot 10^{-10} \mathrm{~m}^{2} / \mathrm{s}$ \\
\hline $\boldsymbol{c}_{\ell}$ at $E_{E x p}$ & \multicolumn{5}{|c|}{$0.237,0.622,0.141$} & mol-fraction $(\mathrm{Ag}, \mathrm{Al}, \mathrm{Cu})$ \\
\hline $\boldsymbol{\Xi}_{A l}, \boldsymbol{\xi}_{A l}, X_{A l}$ & \multicolumn{3}{|l|}{$\left|\begin{array}{ll}2 & 1 \\
1 & 2\end{array}\right|}$, & \multicolumn{2}{|c|}{1.561866} & based on [17, 18] \\
\hline $\boldsymbol{\Xi}_{A g_{2} A l}, \boldsymbol{\xi}_{A g_{2} A l}, X_{A g_{2} A l}$ & {$\left[\begin{array}{ll}2 & 1 \\
1 & 2\end{array}\right]$} & $\begin{array}{l}-3 \\
-2\end{array}$ & & \multicolumn{2}{|c|}{1.427846} & based on [17, 18] \\
\hline $\boldsymbol{\Xi}_{A l_{2} C u}, \boldsymbol{\xi}_{A l_{2} C u}, X_{A l_{2} C u}$ & {$\left[\begin{array}{ll}2 & 1 \\
1 & 2\end{array}\right]$} & $\begin{array}{l}-1 \\
-2\end{array}$ & .395 & \multicolumn{2}{|c|}{0.9176} & based on [17, 18] \\
\hline $\boldsymbol{\Xi}_{\ell}, \boldsymbol{\xi}_{\ell}, X_{\ell}$ & {$\left[\begin{array}{ll}2 & 1 \\
1 & 2\end{array}\right]$} & {$\left[\begin{array}{l}-2 \\
-2\end{array}\right.$} & 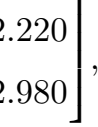 & \multicolumn{2}{|c|}{$3.8655-2 . \overline{6} T$} & based on [17, 18] \\
\hline$T$ at $E_{E x p}$ & \multicolumn{5}{|l|}{1.0} & $773.6 \mathrm{~K}$ \\
\hline$\nabla T$ & \multicolumn{5}{|l|}{$10^{-4}$} & $200 \mathrm{~K} / \mathrm{mm}$ \\
\hline$v$ of $\nabla T$ & \multicolumn{5}{|c|}{$2.1 \cdot 10^{-3}$ cells per time step } & $0.25 \mu \mathrm{m} / \mathrm{s}$ \\
\hline
\end{tabular}

Table 2: Summary of the numerical parameters of the simulations.

\begin{tabular}{lll}
\hline Parameter & Simulation value & Physical value \\
\hline $\mathrm{dx}$ & 1.0 & $3.89 \cdot 10^{-7} \mathrm{~m}$ \\
$\mathrm{dt}$ & 3.2 & $3.2 \cdot 10^{-3} \mathrm{~s}$ \\
$\varepsilon$ & 4.0 & $1.56 \cdot 10^{-6} \mathrm{~m}$ \\
\hline
\end{tabular}




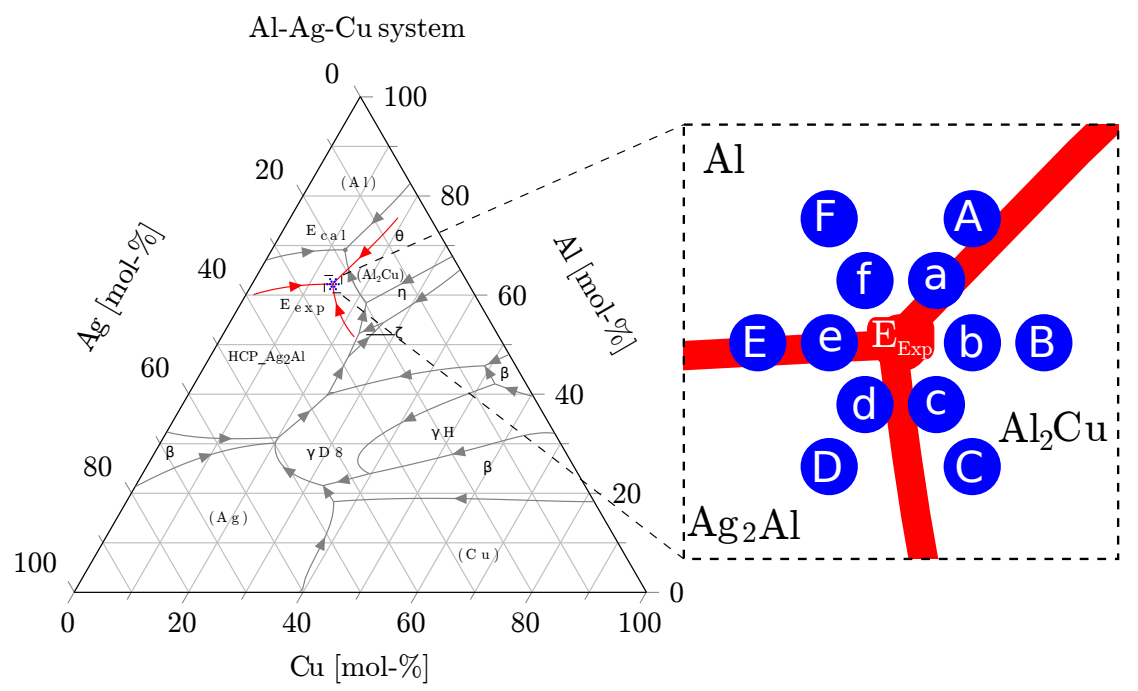

Figure 3: Liquidus projection of the ternary eutectic system $\mathrm{Al}-\mathrm{Ag}-\mathrm{Cu}$, based on [17 18. In red the adjusted ternary eutectic point and the adjusted tie lines are depicted to reproduce the experimentally observed phase fractions, analogously to 23, 25]. The right image magnifies the ternary eutectic region and marks the simulated concentrations a-f, A-F and $E_{E x p}$.

are each executed with 11200 cores for approximately $12 \mathrm{~h}$ on the SuperMUC cluster at the Leibniz supercomputing centre Munich. For all simulations, the parameter sets in tables 1 and 2 are applied. In the simulation results, the $A l$ phase is depicted in red, the $\mathrm{Ag}_{2} \mathrm{Al}$ phase in green and the $\mathrm{Al}_{2} \mathrm{Cu}$ phase in blue.

\subsection{Variation of the melt concentration}

In fig. 4, the solidification fronts at the end of the simulations for the varied concentrations of the melt are shown in their arrangement around the ternary eutectic point $E_{E x p}$. Depending on the variations, different patterns of the three solid phases evolve. An increasing distance of the concentration $\boldsymbol{c}_{\ell}$ from $E_{E x p}$ leads to a more pronounced deviation of the arising patterns. A further change of the melt composition results in two-phase growth. To quantify the visual observation of the pattern modification, the phase fractions and their relative deviation from $E_{E x p}$ (table 3 ) as well as nearest neighbor statistics for $\mathrm{Al}_{2} \mathrm{Cu}$ around $\mathrm{Ag}_{2} \mathrm{Al}$ (fig. $5(\mathrm{a})$ and vice versa (fig. $5(\mathrm{~b})$ are collected. 


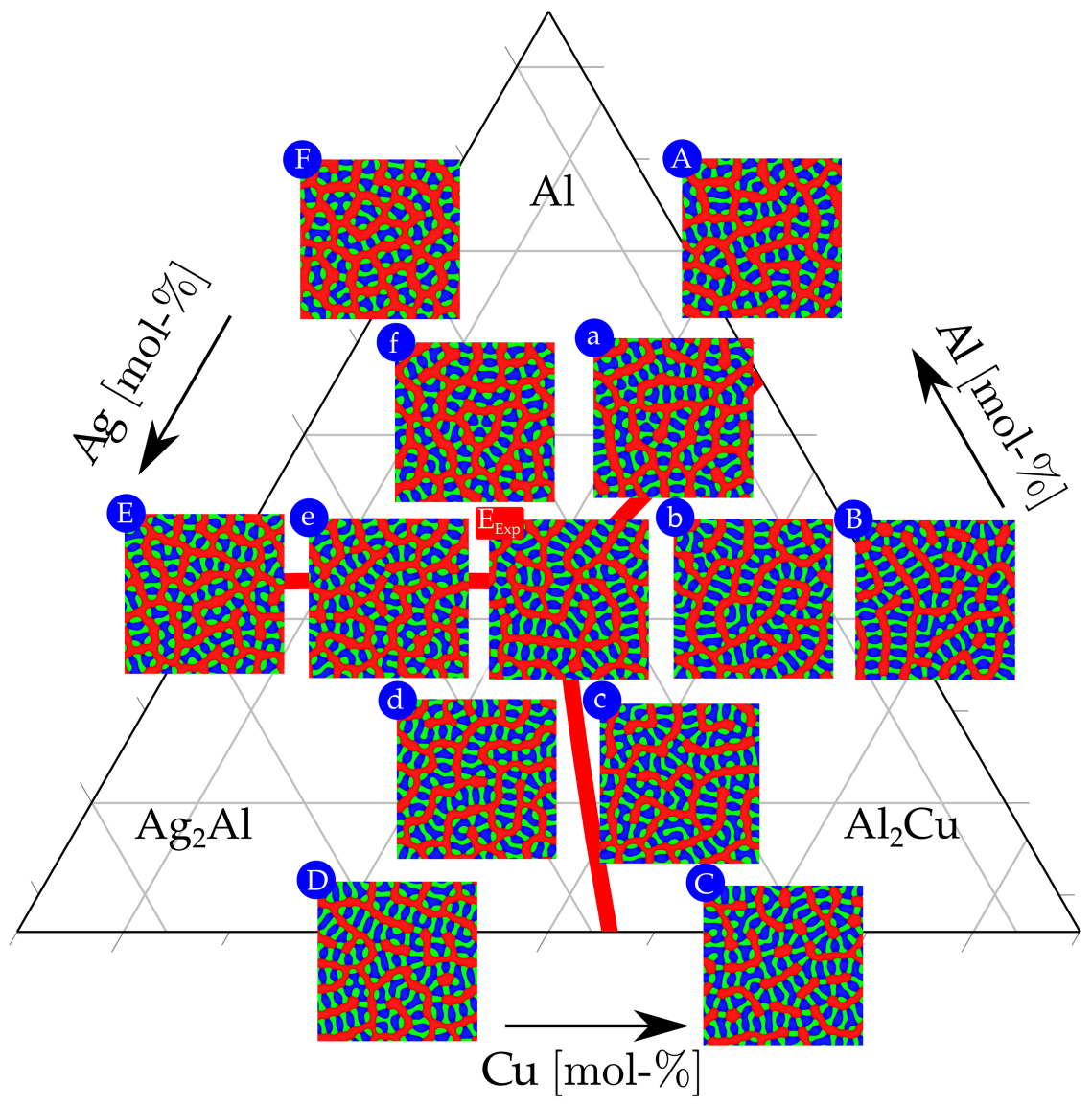

Figure 4: The solidification fronts after 3 million time steps with different concentrations of the melt in their arrangement around the ternary eutectic point $E_{E x p}$. The $A l$ phase is depicted in red, the $\mathrm{Ag}_{2} \mathrm{Al}$ phase in green and the $\mathrm{Al}_{2} \mathrm{Cu}$ phase in blue. One concentration is kept constant and the other two are changed by $\pm 0.5 \%$ (a-f) and $\pm 1 \%$ (A-F) respectively. 
For the quantitative analysis of the simulation results, we focus on the simulations with $\pm 1 \%$ deviation from $E_{E x p}$, indicated by the capital letters A-F, to improve the clarity of the results. However, all observed outcomes are also qualitatively valid for the corresponding simulations a-f. At the ternary eutectic concentration at $E_{E x p}$, the phase fractions of $\mathrm{Al}, \mathrm{Ag} \mathrm{Al}_{2}$ and $\mathrm{Al}_{2} \mathrm{Cu}$ are $35 \%$, $34 \%$ and $31 \%$. Chain-like structures of $\mathrm{Al}_{2} \mathrm{Cu}$ and $\mathrm{Ag}_{2} \mathrm{Al}$ phase arrangements, embedded in an $A l$ matrix evolve, similar to the structures in the left and lower part of the micrograph in fig. 1. Chains appear as two neighboring rods in the nearest neighbor statistics in fig. 5 for $\mathrm{Ag}_{2} \mathrm{Al}$ around $\mathrm{Al}_{2} \mathrm{Cu}$ and vice versa.

The simulations at the compositions $\mathrm{A}, \mathrm{E}$ and $\mathrm{F}$ lead to an increase of the $A l$ phase fraction, incorporated by decreasing fractions of the $\mathrm{Al}_{2} \mathrm{Cu}$ and $\mathrm{Ag} \mathrm{Al}_{2} \mathrm{Al}$ 125 phases. A more pronounced matrix phase with shorter embedded chains, socalled island structures [25], and paw structures [15] evolve. In the simulations, the paw structures occur as $\mathrm{Ag}_{2} \mathrm{Al}$ rods attached to $\mathrm{Al}_{2} \mathrm{Cu}$ lamellae and lead to three and more $\mathrm{Ag}_{2} \mathrm{Al}$ neighbors for each $\mathrm{Al}_{2} \mathrm{Cu}$ lamella as shown in fig. 5(b). Also the number of three and more neighbors in fig. $5(\mathrm{~b})$ respectively the number of one neighbor in fig. $5(\mathrm{a})$, reflects the chain ends. In the simulations A and $\mathrm{F}$ the observed pattern changes are caused by an increase of the $\mathrm{Al}$ amount in the melt. Simulation $\mathrm{E}$ is characterized by a decrease of $\mathrm{Cu}$ and an increase of $\mathrm{Ag}$, which leads to an enrichment of $\mathrm{Al}$ in the melt, due to the different amount of $\mathrm{Al}$ in the phases $\mathrm{Ag}_{2} \mathrm{Al}$ and $\mathrm{Al}_{2} \mathrm{Cu}$.

${ }_{135}$ The shifts of the concentrations towards the $\mathrm{Al}_{2} \mathrm{Cu}$ phase in $\mathrm{B}$ and $\mathrm{C}$, result in a larger fraction of this phase and branched chains, as well as so-called ring-like structures. The junctions, consisting of $\mathrm{Al}_{2} \mathrm{Cu}$ rods, are reflected as three neighbors in fig. 5(b), Analogue to the simulation at $E_{E x p}$, the chains are expressed by the percentage of $77 \%$ in $\mathrm{B}$ and $80 \%$ in $\mathrm{C}$ for two $\mathrm{Al}_{2} \mathrm{Cu}$ neighbors around ${ }_{140} \mathrm{Ag}_{2} \mathrm{Al}$ in the nearest neighbor statistic of fig. 5(a).

In $\mathrm{D}$ a larger amount of $\mathrm{Ag}$ and a constant concentration of $\mathrm{Cu}$ is simulated and results in a larger phase fraction of $\mathrm{Ag}_{2} \mathrm{Al}$. The nearest neighbor statistics as well as the evolving chain-like structures are similar to the simulation at $E_{E x p}$. Despite the constant amount of $\mathrm{Al}$ in the melt of the simulations $\mathrm{B}$ and $\mathrm{E}$, the 
phase fractions of the $A l$ phase change. Due to the different compositions of the solid phases and their interactions, it is not possible to predict the arising patterns just from the overall concentration of the melt. The observed results for the simulations A-F also occur less pronounced in the corresponding simulations a-f.

Table 3: Phase fractions of the simulations A-F and $E_{\text {Exp. }}$.

\begin{tabular}{c|cc|cc|cc}
\hline Simulation & $A l$ & rel. deviation & $\mathrm{Ag}_{2} \mathrm{Al}$ & rel. deviation & $\mathrm{Al}{ }_{2} \mathrm{Cu}$ & rel. deviation \\
\hline$E_{E x p}$ & 0.350 & & 0.309 & & 0.341 & \\
$\mathrm{~A}$ & 0.407 & 0.16 & 0.264 & -0.14 & 0.329 & -0.03 \\
$\mathrm{~B}$ & 0.324 & -0.08 & 0.292 & -0.05 & 0.384 & 0.13 \\
$\mathrm{C}$ & 0.286 & -0.18 & 0.330 & 0.07 & 0.384 & 0.13 \\
$\mathrm{D}$ & 0.325 & -0.07 & 0.343 & 0.11 & 0.332 & -0.03 \\
$\mathrm{E}$ & 0.405 & 0.16 & 0.316 & 0.02 & 0.279 & -0.18 \\
$\mathrm{~F}$ & 0.445 & 0.27 & 0.277 & -0.1 & 0.278 & -0.18 \\
\hline
\end{tabular}

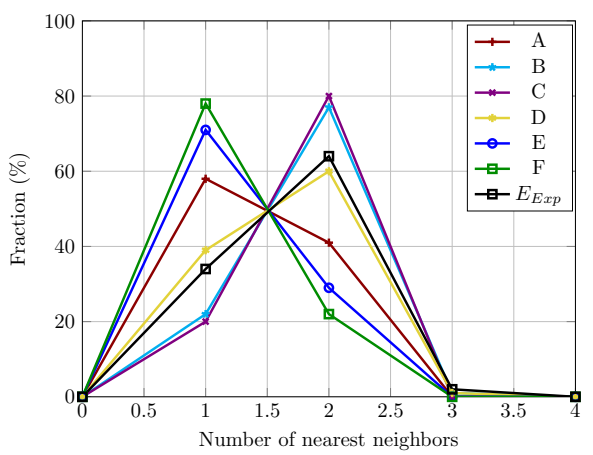

(a) $\mathrm{Al}_{2} \mathrm{Cu}$ adjacent to $\mathrm{Ag}_{2} \mathrm{Al}$

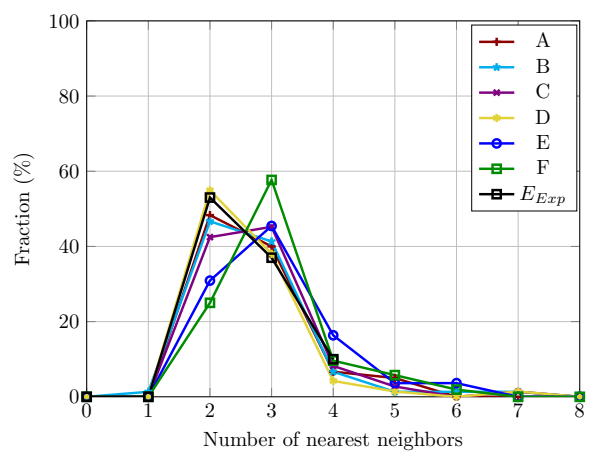

(b) $\mathrm{Ag}_{2} \mathrm{Al}$ adjacent to $\mathrm{Al}_{2} \mathrm{Cu}$

Figure 5: Nearest neighbour statistics of the phase $\mathrm{Al}_{2} \mathrm{Cu}$ adjacent to $\mathrm{Ag}_{2} \mathrm{Al}$ (a) and vice versa (b).

${ }_{150}$ The study indicates, that a variation of the melt concentration of $\pm 0.5 \%$ and $\pm 1 \%$ from the ternary eutectic composition results in visual and measurable pat- 
tern change. In fig. 6 the three-dimensional microstructures for the simulations A-F are depicted. The lower 2D transverse sections exempt the solidification fronts after one and two millions time steps. Between one and two million time steps only small changes of the microstructure occur. In the following one million iterations, till the end of the simulations, the phase arrangements and the form of the rods grow in stationary states. We conclude that a variation of the concentration in the melt leads to the growth of several, stable patterns.

\subsection{Approach to an explanation of complex pattern formation in experiments}

During directional solidification experiments of ternary eutectic systems, like Al-Ag-Cu, various patterns evolve [6, 11, 15]. Even in a single micrograph, different patterns can be observed as exemplary shown in fig. 1 and in fig. 7 . In the experimental micrographs of $\mathrm{Al}-\mathrm{Ag}-\mathrm{Cu}$ in fig. 7, three regions I-III can be distinguished, which probably consist of different grains. In each of these regions, different phase fractions and patterns occur. On the left side, a general view of the directional solidified sample and on the right side, a detailed micrograph of the region with three different patterns is depicted.

In table 4 the phase fractions and their relative deviation from $E_{E x p}$ in table 3 are listed. The phase fractions in region I of table 4 differ less than $1 \%$ for all phases from the simulated results at $E_{\text {Exp }}$. Both nearest neighbor statistics in fig. 8 show a peak at two neighbors for $E_{E x p}$ as well as for region I. Based on these statistics as well as the occurring microstructure, the experimentally observed results in region $I$ are in accordance with the simulation at $E_{E x p}$. The results of region II show a similar tendency as in simulation D, which corre175 sponds to an increase of $\mathrm{Ag}$ in the melt concentration. The deviation from the simulation at $E_{E x p}$ is more pronounced in the experimental region II, than in the simulation D. In region III, the phase fractions deviation show a trend similar to simulation B. In all regions I-III, variations of chain-like structures can be observed visually as well as with nearest neighbor statistics.

${ }_{180}$ To further quantify the observed variations of the microstructure, a principal component analysis (PCA), based on two-point correlations is conducted [40- 


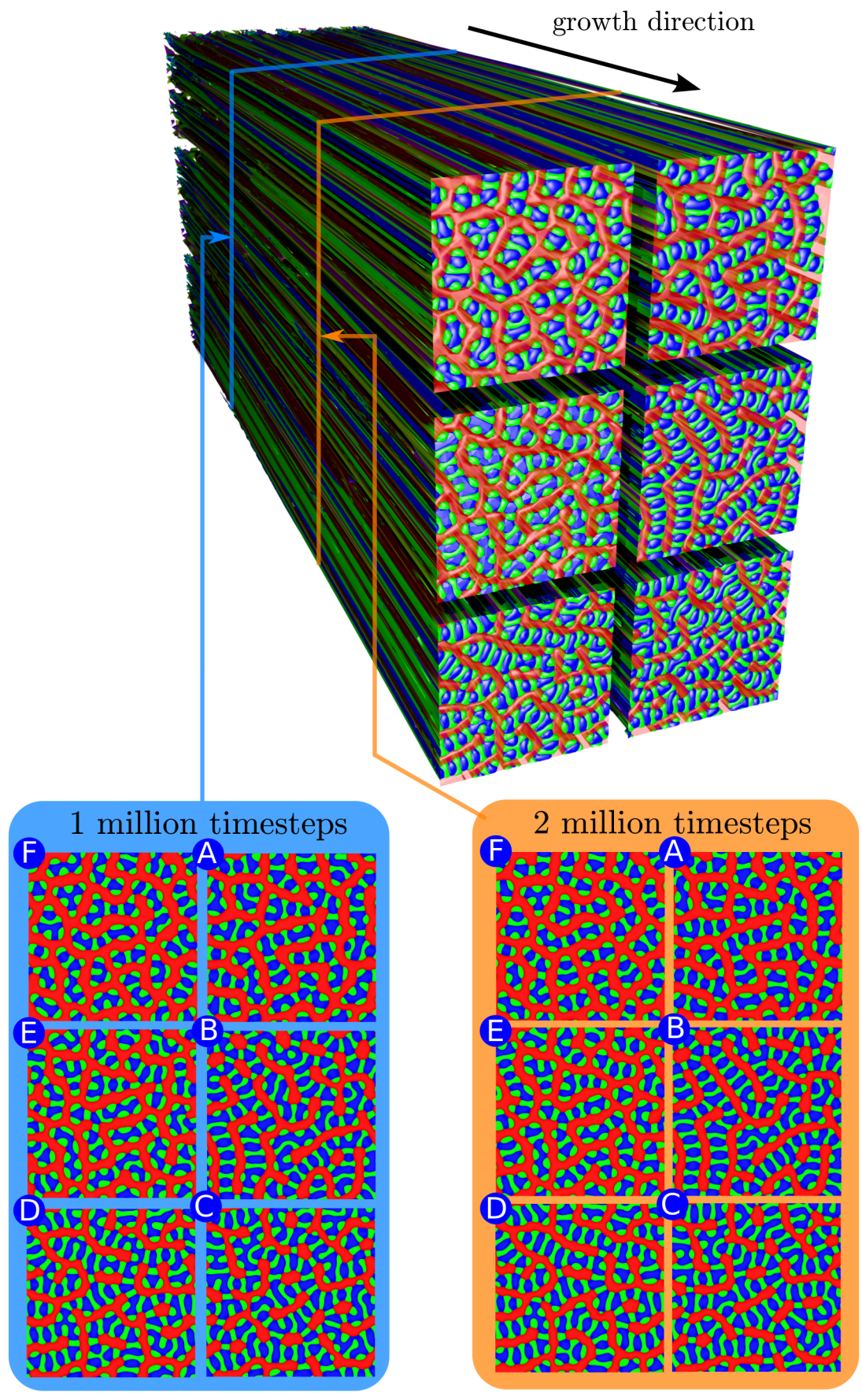

Figure 6: The three-dimensional microstructure of the three solid phases for the simulations A-F are shown. Below, the solidification fronts after 1 and 2 million time steps are extracted. 

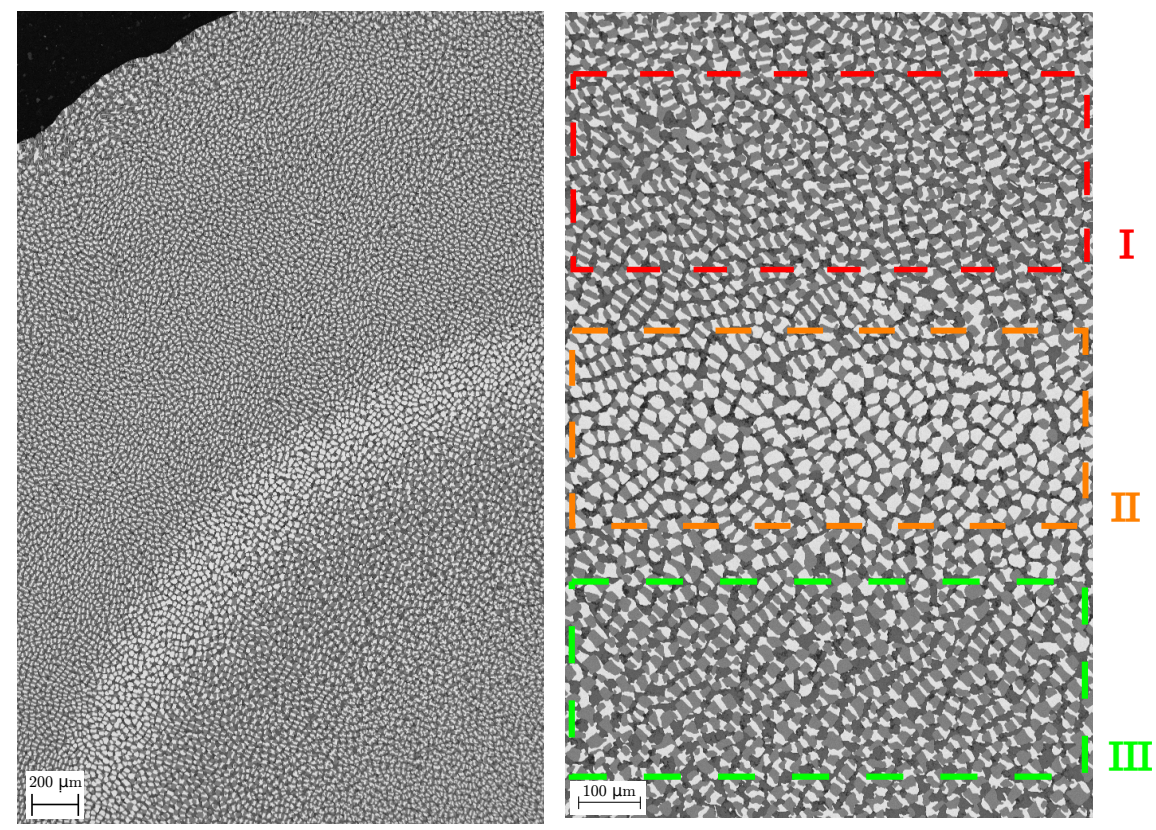

Figure 7: Directional solidified experimental transverse sections of $\mathrm{Al}-\mathrm{Ag}-\mathrm{Cu}$ parallel to the growth front. The sample solidified with a velocity of $0.11 \mu \mathrm{m} / \mathrm{s}$ and a gradient of $2.2 \mathrm{~K} / \mathrm{mm}$. The composition of the melt was measured to be at the ternary eutectic point. Left, a general view of the directional solidified sample and right, a detailed micrograph of the region with three different patterns is depicted.

48. The two-point correlations describe the probability that two points on a plane have defined characteristics, depending on their relative positions. The set of all two-point correlations is projected in the direction of the highest variances, which generates the highly non-linear principal component (PC) space. The capability of this method to analyze microstructure evolutions is demonstrated in 26]. The same procedure as in 26] is applied to the simulations a-f, A-F and $E_{E x p}$ as well as to the different regions I-III of the experimental micrograph. In fig. 9 the projection of the results in the three PC directions with the highest variance are plotted.

In both projections, the arrangement and the order of the simulations A-F around $E_{E x p}$ is reflected. Similar to the visually observation and the measured phase fractions, the PCA shows the accordance between the simulation $E_{E x p}$ 
Table 4: Phase fractions at the different regions of fig. 7. I-III and their relative deviation from the simulation at $E_{E x p}$.

\begin{tabular}{c|cc|cc|cc}
\hline & $\mathrm{Al}$ & rel. deviation & $\mathrm{Ag}_{2} \mathrm{Al}$ & rel. deviation & $\mathrm{Al}{ }_{2} \mathrm{Cu}$ & rel. deviation \\
\hline I & 0.347 & -0.01 & 0.303 & -0.02 & 0.35 & 0.03 \\
II & 0.306 & -0.13 & 0.479 & 0.55 & 0.215 & -0.37 \\
III & 0.348 & -0.01 & 0.273 & -0.12 & 0.379 & 0.11 \\
\hline
\end{tabular}

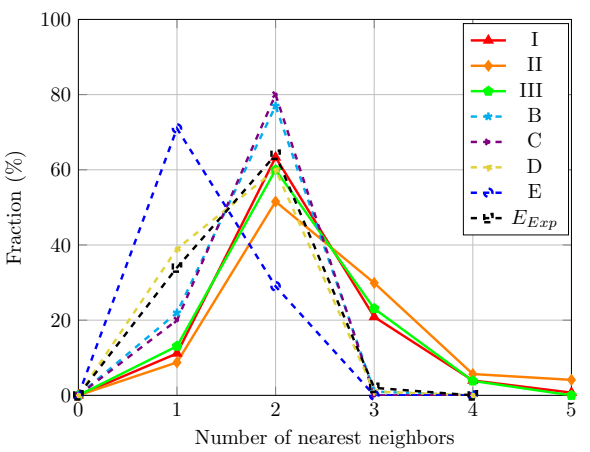

(a) $\mathrm{Al}_{2} \mathrm{Cu}$ adjacent to $\mathrm{Ag}_{2} \mathrm{Al}$

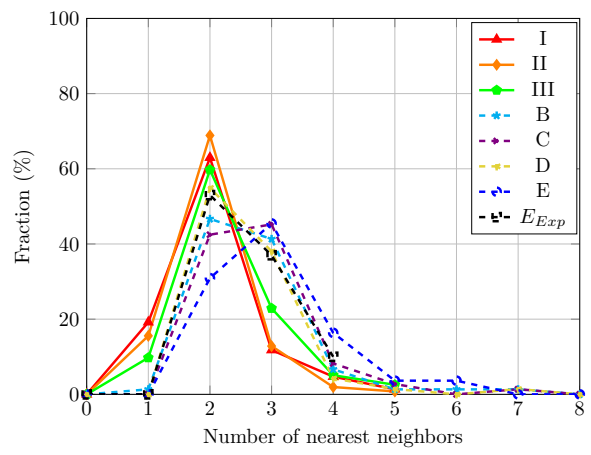

(b) $\mathrm{Ag}_{2} \mathrm{Al}$ adjacent to $\mathrm{Al}_{2} \mathrm{Cu}$

Figure 8: Nearest neighbour statistics of the phase $\mathrm{Al}_{2} \mathrm{Cu}$ adjacent to $\mathrm{Ag}_{2} \mathrm{Al}$ (a) and vice versa (b) for the different regions of fig. 7 I-III and selected simulations.

and region I, due their relative location. Like $E_{E x p}$, the projection of region I is framed by the representations of the simulations A-F.

The PCA results for region II and III are in accordance with the tendencies of the previous statistics. Based on $E_{E x p}$, in both plots the projection of region II is located in the direction of the simulations $\mathrm{D}$ and $\mathrm{E}$, whereas the projection of region III lies in the direction of the simulations B and C. It is shown that the pattern change as well as the shift of the phase fraction is reflected with the principal component analysis.

Due to the mentioned tendencies from various analyses of the regions I-III and of the simulations with different melt concentrations, we suppose, that the variations of the chain-like patterns depend on local concentration deviations. One 


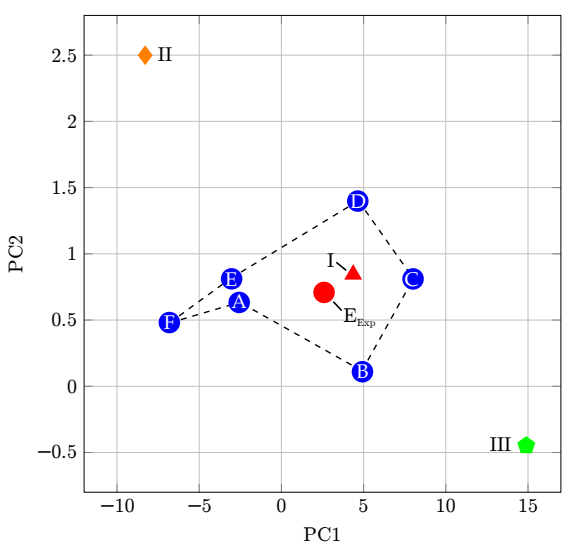

(a) $P C 1$ and $P C 2$

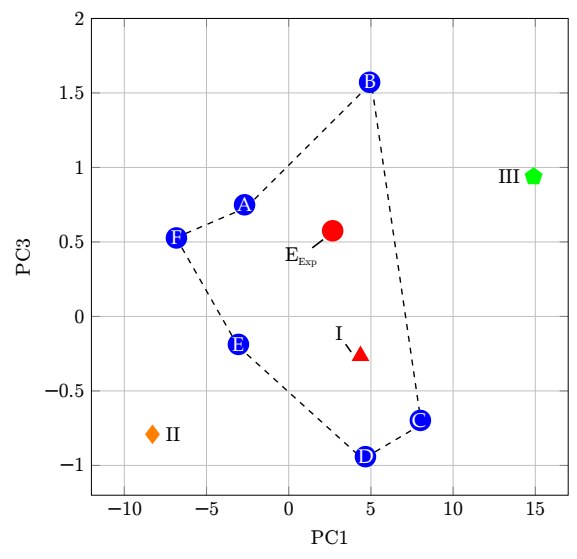

(b) $P C 1$ and $P C 3$

Figure 9: Projection of the simulation at $E_{E x p}$, the simulations A-F and three different regions I-III from the experimental micrograph in the PC1 and PC2 plane as well as the PC1 and PC3 plane.

205 the melt is systematically varied around the ternary eutectic point $E_{E x p}$ in the range of $\pm 1 \%$. For this, large-scale phase-field simulations are conducted to gain statistical volume elements. 
tions and principal component analysis (PCA) based on two-point correlations are applied. Based on these we draw our five main conclusions: (i) Variations of the melt concentration of $\pm 1 \%$ lead to different patterns. (ii) All simulations evolve in a stationary state for the different arising patterns. (iii) In the investigated range, the arising patterns at $\pm 1 \%$ show similar, but enhanced tendencies as the corresponding simulations at $\pm 0.5 \%$. (iv) The results from the PCA reflect the arrangement of the concentration variation around the ternary eutectic point and allow to determine a quantitative relation between different micrographs. (v) In the presented experimental micrograph, the same tendencies of the patterns and phase fractions like in the simulative study with different melt concentrations are observed. Following these results, we conclude, that local deviations in the concentration of the melt can result in different patterns within the same micrograph as experimentally observed.

\section{Acknowledgements}

We thank the Leibniz Supercomputing Centre in Munich for computational resources, provided as part of a Large Scale Gauss Project. Philipp Steinmetz and Anne Dennstedt thank for financial support through the German Research Foundation within the project NE 822/14-2 and RA 537/14-2. Johannes Hötzer and Britta Nestler acknowledge the funding of the cooperative graduate school "Gefügeanalyse und Prozessbewertung" by the ministry of BadenWuerttemberg. Michael Kellner is grateful to the funding of the Helmholtz research school "Integrated Materials Development for Novel High-Temperature Alloys". We also would like to thank Martin Bauer for helping to implement the solver in the WALBERLA framework. We are grateful to Surya R. Kalidindi and ${ }_{245}$ Yuksel Yabansu for the many interesting and fruitful discussion about principal component analysis as well as Laura Promberger for the implementation in our framework. 


\section{References}

[1] C. Rios, S. Milenkovic, S. Gama, R. Caram, Influence of the growth rate on the microstructure of a $\mathrm{Nb}-\mathrm{Al}-\mathrm{Ni}$ ternary eutectic, Journal of crystal growth 237 (2002) 90-94.

[2] U. Böyük, N. Marasli, Dependency of eutectic spacings and microhardness on the temperature gradient for directionally solidified $\mathrm{Sn}-\mathrm{Ag}-\mathrm{Cu}$ lead-free solder, Materials Chemistry and Physics 119 (2010) 442-448.

[3] U. Böyük, Physical and mechanical properties of Al-Si-Ni eutectic alloy, Metals and Materials International 18 (2012) 933-938.

[4] M. A. Ruggiero, J. W. Rutter, Origin of microstructure in the $332 \mathrm{~K}$ eutectic of the Bi-In-Sn system, Materials Science and Technology 13 (1997) $5-11$.

[5] D. Lewis, S. Allen, M. Notis, A. Scotch, Determination of the eutectic structure in the Ag-Cu-Sn system, Journal of Electronic Materials 31 (2002) 161-167.

[6] D. Cooksey, A. Hellawell, The Microstructures of Ternary Eutectic Alloys in the Systems Cd-Sn-(Pb, In, Tl), Al-Cu-(Mg, Zn, Ag) and Zn-Sn-Pb, Journal of the Institute of Metals 95 (1967) 183-187.

[7] D. McCartney, R. Jordan, J. Hunt, The structures expected in a simple ternary eutectic system: Part II. The Al-Ag-Cu ternary system, Metallurgical Transactions A 11 (1980) 1251-1257.

[8] U. Böyük, N.Marasli, H.Kaya, E.Cadirli, K. Keslioglu, Directional solidification of Al-Cu-Ag alloy, Applied Physics A 95 (2009) 923-932.

[9] S. J. De Wilde, L.Froyen, Coupled two phase $\left[\alpha(\mathrm{Al}]+\theta\left(A l_{2} C u\right)\right]$ planar growth and destabilisation along the univariant eutectic reaction in $\mathrm{Al}-\mathrm{Cu}-$ Ag alloys, Scripta Materialia 51 (2004) 533-538. 
[10] A. L. Genau, L. Ratke, Crystal orientation and morphology in $\mathrm{Al}-\mathrm{Ag}-\mathrm{Cu}$ ternary eutectic, IOP Conference Series: Materials Science and Engineering 27 (2012) 012032.

[11] A. Genau, L. Ratke, Morphological characterization of the Al-Ag-Cu ternary eutectic, International Journal of Materials Research 103 (2012) 469-475.

[12] A. Dennstedt, L. Ratke, Microstructures of directionally solidified Al-Ag$\mathrm{Cu}$ ternary eutectics, Transactions of the Indian Institute of Metals 65 (2012) 777-782.

[13] A. Dennstedt, L. Ratke, A. Choudhury, B. Nestler, New metallographic method for estimation of ordering and lattice parameter in ternary eutectic systems, Metallography, Microstructure, and Analysis 2 (2013) 140-147.

[14] I. Sargin, Invariant and univariant eutectic solidification in ternary alloys, Ph.D. thesis, Iowa State University, 2015.

[15] A. Dennstedt, A. Choudhury, L. Ratke, B. Nestler, Microstructures in a ternary eutectic alloy: devising metrics based on neighbourhood relationships, in: IOP Conference Series: Materials Science and Engineering, volume 117, IOP Publishing, 2016, p. 012025.

[16] A. Dennstedt, L. Helfen, P. Steinmetz, B. Nestler, L. Ratke, 3D Synchrotron Imaging of a Directionally Solidified Ternary Eutectic, Metallurgical and Materials Transactions A 47 (2015) 981-984.

[17] V. Witusiewicz, U. Hecht, S. Fries, S. Rex, The Ag-Al-Cu system: Part I: Reassessment of the constituent binaries on the basis of new experimental data, Journal of alloys and compounds 385 (2004) 133-143.

[18] V. Witusiewicz, U. Hecht, S. Fries, S. Rex, The Ag-Al-Cu system: Part II: A thermodynamic evaluation of the ternary system, Journal of alloys and compounds 387 (2005) 217-227. 
[19] B. Nestler, H. Garcke, B. Stinner, Multicomponent alloy solidification: phase-field modeling and simulations, Physical Review E 71 (2005) 041609.

[20] A. Choudhury, M. Plapp, B. Nestler, Theoretical and numerical study of lamellar eutectic three-phase growth in ternary alloys, Physical Review E 83 (2011) 051608.

[21] J. Hötzer, P. Steinmetz, M. Jainta, S. Schulz, M. Kellner, B. Nestler, A. Genau, A. Dennstedt, M. Bauer, H. Köstler, U. Rüde, Phase-field simulations of spiral growth during directional ternary eutectic solidification, Acta Materialia 106 (2016) 249-259.

[22] P. Steinmetz, J. Hötzer, M. Kellner, A. Dennstedt, B. Nestler, Largescale phase-field simulations of ternary eutectic microstructure evolution, Computational Materials Science 117 (2016) 205-214.

[23] A. Choudhury, Pattern-formation during self-organization in three-phase eutectic solidification, Transactions of the Indian Institute of Metals 68 (2015) 1137-1143.

[24] M. Apel, B. Böttger, V. Witusiewicz, U. Hecht, I. Steinbach, Lamellar Pattern Formation during 2D-Directional Solidification of Ternary Eutectic Alloys, Solidification and Crystallization (2004) 271-279.

[25] J. Hötzer, M. Jainta, P. Steinmetz, B. Nestler, A. Dennstedt, A. Genau, M. Bauer, H. Köstler, U. Rüde, Large scale phase-field simulations of directional ternary eutectic solidification, Acta Materialia 93 (2015) 194204.

[26] P. Steinmetz, Y. Yabansu, J. Hötzer, M. Jainta, B. Nestler, S. Kalidindi, Analytics for microstructure datasets produced by phase-field simulations, Acta Materialia 103 (2016) 192-203.

[27] M. Plapp, Unified derivation of phase-field models for alloy solidification from a grand-potential functional, Physical Review E 84 (2011) 031601. 
[28] A. Choudhury, B. Nestler, Grand-potential formulation for multicomponent phase transformations combined with thin-interface asymptotics of the double-obstacle potential, Physical Review E 85 (2012) 021602.

[29] A. Choudhury, M. Kellner, B. Nestler, A method for coupling the phase-field model based on a grand-potential formalism to thermodynamic databases, Current Opinion in Solid State and Materials Science 19 (2015) $287-300$.

[30] A. Karma, Phase-field formulation for quantitative modeling of alloy solidification, Physical Review Letter 87 (2001) 115701.

[31] B. Echebarria, R. Folch, A. Karma, M. Plapp, Quantitative phase-field model of alloy solidification, Physical Review E 70 (2004) 061604.

[32] J. Hötzer, O. Tschukin, M. B. Said, M. Berghoff, M. Jainta, G. Barthelemy, N. Smorchkov, D. Schneider, M. Selzer, B. Nestler, Calibration of a multiphase field model with quantitative angle measurement, Journal of Materials Science 51 (2016) 1788-1797.

[33] M. Bauer, J. Hötzer, M. Jainta, P. Steinmetz, M. Berghoff, F. Schornbaum, C. Godenschwager, H. Köstler, B. Nestler, U. Rüde, Massively parallel phase-field simulations for ternary eutectic directional solidification, Proceedings of the International Conference for High Performance Computing, Networking, Storage and Analysis (2015) 8.

[34] H. Garcke, B. Nestler, B. Stinner, A diffuse interface model for alloys with multiple components and phases, SIAM J. APPL. MATH. 64 (2004) $775-779$.

[35] J. Hötzer, O. Tschukin, M. B. Said, M. Berghoff, M. Jainta, G. Barthelemy, N. Smorchkov, D. Schneider, M. Selzer, B. Nestler, Calibration of a multiphase field model with quantitative angle measurement, Journal of Materials Science 51 (2016) 1788-1797. 
[36] A. Bulla, C. Carreno-Bodensiek, B. Pustal, R. Berger, A. Bührig-Polaczek, A. Ludwig, Determination of the Solid-Liquid Interface Energy in the Al-Cu-Ag System, Metallurgical and Materials Transactions A 38 (2007) 1956-1964.

[37] D. M. Herlach, R. Kirchheim (Eds.), Phase Transformations in Multicomponent Melts, 1. edition ed., Wiley-VCH Verlag GmbH \& Co. KGaA, 2008.

[38] T. Himemiya, T. Umeda, Three-phase planar eutectic growth models for a ternary eutectic system, Materials transactions-JIM 40 (1999) 665-674.

[39] K. Kim, J. Liu, N. Marasli, J. Hunt, The effect of different atomic volumes in the three phases during lamellar eutectic growth. a comparison of experiment and theory in the $\mathrm{Al}-\mathrm{Al}_{2} \mathrm{Cu}$ system, Acta metallurgica et materialia 43 (1995) 2143-2147.

[40] S. Niezgoda, D. Fullwood, S. Kalidindi, Delineation of the space of 2-point correlations in a composite material system, Acta Materialia 56 (2008) 5285-5292.

[41] S. R. Niezgoda, Y. C. Yabansu, S. R. Kalidindi, Understanding and visualizing microstructure and microstructure variance as a stochastic process, Acta Materialia 59 (2011) 6387-6400.

[42] T. Fast, S. R. Niezgoda, S. R. Kalidindi, A new framework for computationally efficient structure-structure evolution linkages to facilitate high-fidelity scale bridging in multi-scale materials models, Acta Materialia 59 (2011) 699-707.

[43] S. R. Niezgoda, A. K. Kanjarla, S. R. Kalidindi, Novel microstructure quantification framework for databasing, visualization, and analysis of microstructure data, Integrating Materials and Manufacturing Innovation 2 (2013) 1-27.

[44] A. Çeçen, T. Fast, E. C. Kumbur, S. R. Kalidindi, A data-driven approach to establishing microstructure-property relationships in porous transport 
layers of polymer electrolyte fuel cells, Journal of Power Sources 245 (2014) $144-153$.

[51] S. Rex, ACCESS e.V., RWTH Aachen, SETA - Das Erstarrungsverhalten von mehrkomponentigen Legierungen, 2014-03-07. URL:

口

[45] S. R. Kalidindi, Hierarchical Materials Informatics - Novel Analytics for Materials Data, Butterworth Heinemann, 2015.

[46] S. R. Kalidindi, Data science and cyberinfrastructure: critical enablers for accelerated development of hierarchical materials, International Materials Reviews 60 (2015) 150-168.

[47] S. R. Kalidindi, J. A. Gomberg, Z. T. Trautt, C. A. Becker, Application of data science tools to quantify and distinguish between structures and models in molecular dynamics datasets, Nanotechnology 26 (2015) 344006.

[48] A. Gupta, A. Cecen, S. Goyal, A. K. Singh, S. R. Kalidindi, Structureproperty linkages using a data science approach: Application to a nonmetallic inclusion/steel composite system, Acta Materialia 91 (2015) 239254.

[49] R. Mehrabian, M. Keane, M. Flemings, Interdendritic fluid flow and macrosegregation; influence of gravity, Metallurgical and Materials Transactions 1 (1970) 1209-1220.

[] J. R. Carruthers, L. R. Testardi, Materials processing in the reducedgravity environment of space, Annual Review of Materials Science 13 (1983) $247-278$.

[50] P. V. Morokhov, V. M. Ananin, A. A. Ivannikov, O. N. Sevryukov, A. N. Suchkov, Gravity-induced macro-segregation of melt and its effect on viscosity and differential thermal analysis, Tsvetnye Metally (Non-ferrous metals) 12 (2014).

http://www.dlr.de/dlr/desktopdefault.aspx/tabid-10337/1346_ read-10047//usetemplate-print/, accessed: 2016-02-25. 
[52] R. Rojas, T. Takaki, M. Ohno, A phase-field-lattice boltzmann method for modeling motion and growth of a dendrite for binary alloy solidification in the presence of melt convection, Journal of Computational Physics 298 (2015) 29-40.

${ }_{415}$ [53] T. Takaki, R. Rojas, M. Ohno, T. Shimokawabe, T. Aoki, GPU phasefield lattice boltzmann simulations of growth and motion of a binary alloy dendrite, IOP Conference Series: Materials Science and Engineering 84 (2015) 012066. 